\title{
ATUAÇÃO INTERDISCIPLINAR NO PROJETO RONDON: OPERAÇÃO PORTA DO SOL
}

\author{
Joice de Abreu Brandolfi ${ }^{1}$, Nathaly Willemann Medeiros ${ }^{2}$, Évelin Vicente ${ }^{3}$
}

\section{INTRODUÇÃO}

O Projeto Rondon, sob coordenação do Ministério da Defesa, é conduzido em estreita parceria com o Ministério da Educação, o Ministério do Desenvolvimento Social e Agrário, o Ministério da Saúde, o Ministério do Meio Ambiente, o Ministério da Integração Nacional, o Ministério do Esporte e a Secretaria de Governo da Presidência da República, com o objetivo de promover o contato de estudantes universitários voluntários com o interior do País por meio de atividades em comunidades isoladas e carentes (REBELATO, 2010).

O Projeto prioriza, assim, desenvolver ações que tragam benefícios permanentes para as comunidades, principalmente as relacionadas com a melhoria do bem estar social e a capacitação da gestão pública. Busca, ainda, consolidar no universitário brasileiro o sentido de responsabilidade social, coletiva, em prol da cidadania, do desenvolvimento e da defesa dos interesses nacionais, contribuindo na sua formação acadêmica e proporcionando-lhe o conhecimento da realidade brasileira (SOUZA, 2005).

O Projeto Rondon surgiu em 1966 como um movimento de mobilização da juventude, que envolveu a tríade: o universitário, a universidade e a integração nas áreas de atuação. Sua finalidade era a de promover estágios de serviço para estudantes universitários, objetivando conduzir a juventude a participar do processo de integração nacional (RODRIGUES, 2008).

É um programa integracionista, baseado na filosofia humanística do Marechal Cândido Mariano da Silva Rondon (TOMAS, 2007). Os participantes do projeto são chamados de rondonistas, que são as pessoas envolvidas no projeto, podem exercer atividades

\footnotetext{
${ }^{1}$ Graduanda em Fisioterapia pela Universidade do Extremo Sul Catarinense. Membro do Laboratório de Biomecânica (Labiomec) - UNESC. Membro do Programa de Atuação Interdisciplinar Uroginecológica (Proauro). Voluntária no projeto de extensão Bem Viver com Alzheimer - UNESC. Membro da Liga de Fisioterapia em Pediatria (Lafipe) - UNESC.

${ }^{2}$ Graduanda em Fisioterapia pela Universidade do Extremo Sul Catarinense. Membro do Programa de Atenção Interdisciplinar Uroginecológica (Proauro) - UNESC. Voluntária no projeto de extensão Bem Viver com Alzheimer - UNESC. Membro da Liga de Fisioterapia em Pediatria (Lafipe) - UNESC.

${ }^{3}$ Docente do Curso de Fisioterapia da Universidade do Extremo Sul Catarinense - UNESC.
} 
no Conjunto A: Cultura, Direitos Humanos e Justiça, Educação e Saúde, ou no Conjunto B: Comunicação, Tecnologia e Produção, Meio Ambiente e Trabalho.

A Universidade do Extremo Sul Catarinense - UNESC, localizada em Criciúma-SC se fez presente na Operação Porta do Sol, no município de Itapororoca-Paraíba/PB entre Janeiro e Fevereiro de 2015 com um grupo formado por dois professores e, por oito estudantes selecionados atuando no conjunto A (TOMAS, 2007).

Segundo dados do Instituto Brasileiro de Geografia e Estatística (IBGE), o município de Itapororoca está localizado na Microrregião Itapororoca e na Mesorregião Mata Paraibana do Estado da Paraíba. Sua área é de $146 \mathrm{~km}^{2}$ representando $0.2588 \%$ do Estado, 0.0094\% da Região e $0.0017 \%$ de todo o território brasileiro.

No ano de 2010 no ultimo censo realizado, a população do município de Itapororoca dividia-se entre 64\% Urbana e 36\% rural, totalizando 16.998 habitantes. Segundo o Atlas de Desenvolvimento Humano, o IDH do município apresenta bons resultados no fator Longevidade, porem resultados insatisfatórios na Renda e Educação, alcançando um índice geral de 0,564 classificado como IDH baixo apesar de um crescimento bastante significativo nas duas últimas décadas.

O objetivo do estudo, é mostrar as vivências e experiências no município e a prática da extensão na sua total integralidade, com trocas de conhecimentos e experiências em áreas multidisciplinares em uma comunidade de um município do Brasil com condições econômicas desfavoráveis, quando comparado a outras regiões do país.

\section{METODOLOGIA}

Trata-se de um estudo quantitativo, exploratório e descritivo baseado na forma relato de experiência e vivência. Realizado durante o Projeto Rondon - Operação Porta do Sol, na cidade de Itapororoca-Paraíba/PB no período de 27 de Janeiro de 2015 a 06 de fevereiro de 2015. Foram realizadas palestras na área da Cultura, Direitos Humanos e Justiça, Educação e Saúde, apresentação de teatro e cinema e caminhada ao pôr do sol para a comunidade, assim como orientações nas diversas áreas assistidas.

Estas atividades ocorreram no período diurno, vespertino e noturno, com entrega de certificados. Participaram do projeto professores e alunos da UNESC e, a comunidade do município de Itapororoca-PB. Os resultados das atividades executadas foram expressos em porcentagem. 
As atividades foram organizadas pelos professores do projeto em conjunto com os alunos participantes, através da discussão e debate de ideias, após a problematização e análise de prioridades através das necessidades apontadas pelo município.

\section{RESULTADOS}

Durante o período de 27 de janeiro de 2015 a 06 de fevereiro de 2015 foram realizadas palestras na área da Cultura, Saúde (Figura 1), Educação, Direitos Humanos e Justiça, apresentação de teatro e cinema, caminhada ao pôr do sol para a comunidade. Estas atividades ocorreram no período diurno, vespertino e noturno, com entrega de certificados. Participaram crianças, adultos e idosos da comunidade.

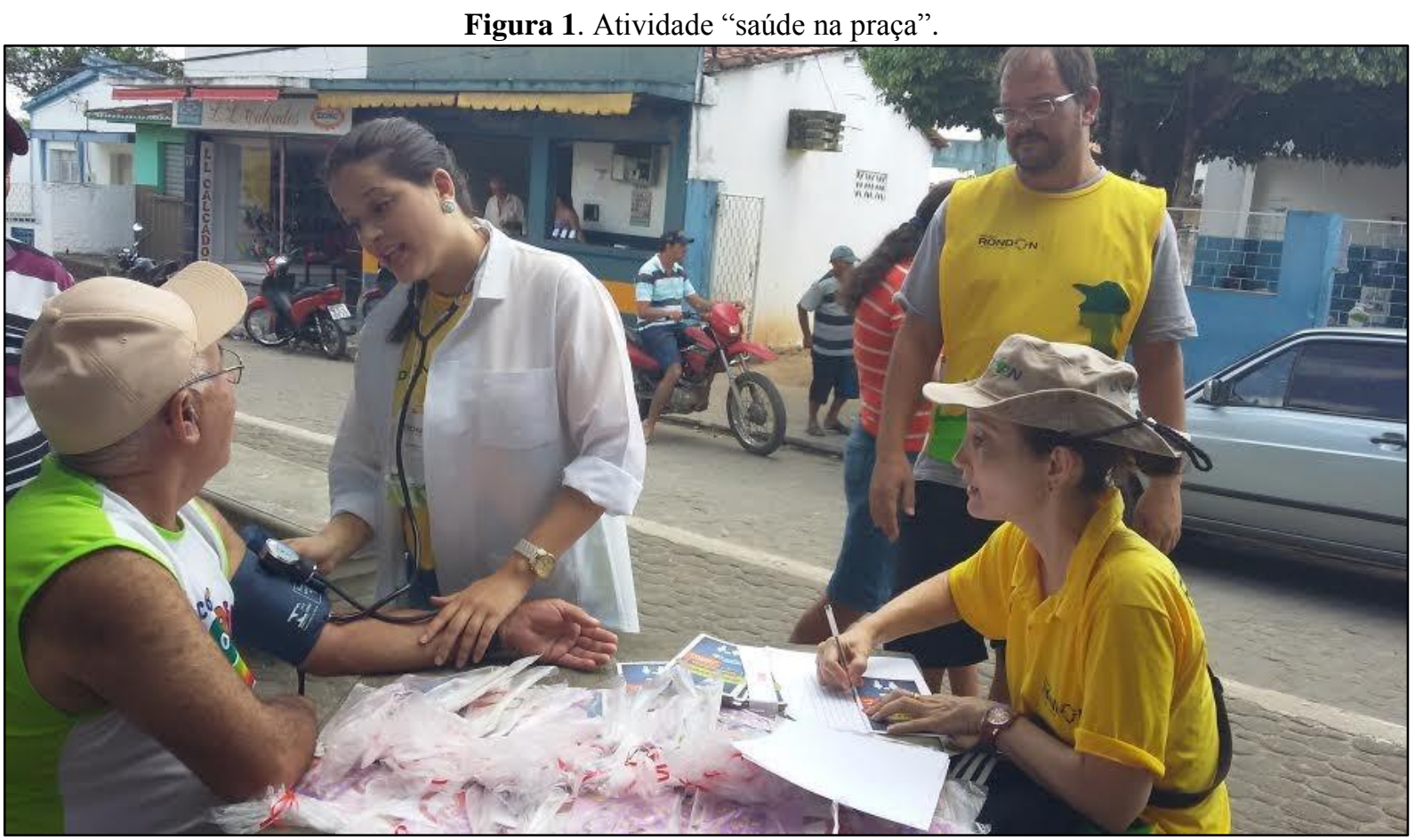

Fonte: Arquivo do autor.

Nas atividades relacionadas à cultura obteve-se a participação de $24 \%$ da comunidade, na saúde 52\%, educação $19 \%$ e direitos humanos 5\%, como mostra a Figura 2. 
Figura 2. Percentual de participação da comunidade nas atividades desenvolvidas pelo Projeto Rondon.

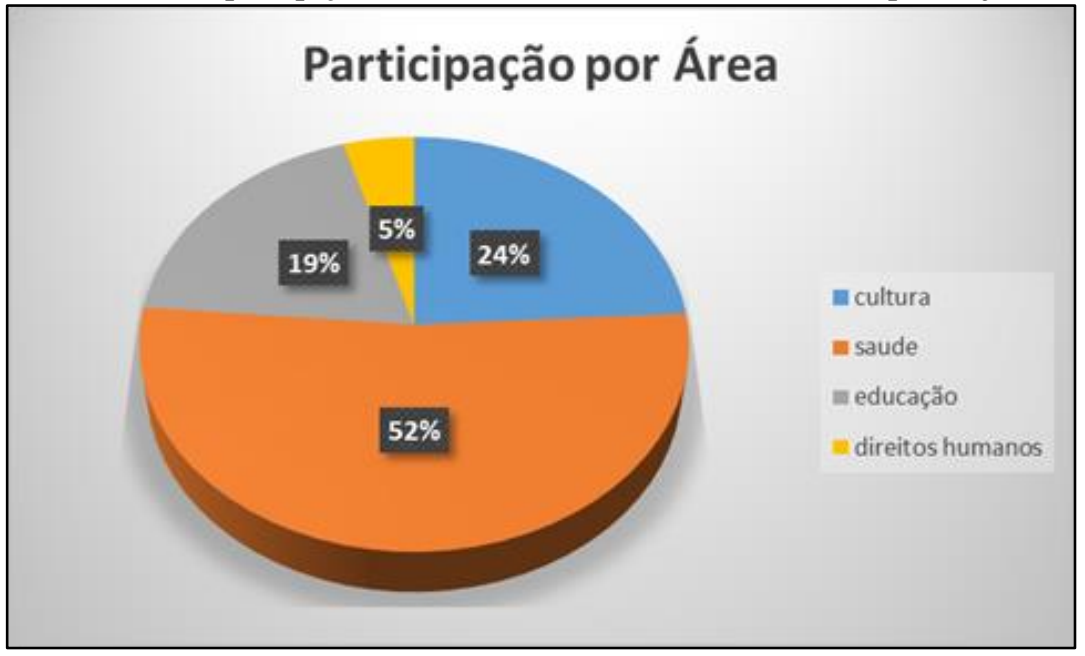

Fonte: Desenvolvido pelo autor.

\section{DISCUSSÕES}

Atualmente no Brasil, conforme menções de Forproex (2006), agentes da educação superior buscam transcender os muros de isolamento erguidos no entorno de suas instituições. Para tanto, redefinem as práticas de ensino, pesquisa e extensão, ampliando o público envolvido. Passando-se a questionar mais as ações propostas pelas universidades.

O Projeto Rondon é uma concepção operacional de extensão universitária, interativa e integrativa entre professores e alunos das universidades e com as comunidades, desde as mais próximas (entorno, mesma localidade ou região) até as mais distantes geograficamente (distintas regiões, diferentes estados, diferentes países). A comunidade externa não apenas recebe benefícios, mas contribui com as universidades, realimentado-a para a revisão de seu papel no desenvolvimento integral e sustentador das sociedades, assim como possibilita o contato estreito, intenso e prático dos estudantes com a realidade (SOUZA, 2005).

Santos e Mendes (2005) sugerem que o foco do Projeto Rondon foi se consolidando rapidamente nos primeiros anos de atuação com a concepção, implantação e exercício dos vários programas operacionais desenvolvidos.

A participação efetiva dos acadêmicos enquanto graduandos em projetos de extensão universitária, como o promovido pelo Projeto Rondon, através da Operação Porta do Sol, remete a importância da realização de atividades além do espaço universitário, proporcionando uma maior integração com a comunidade.

Para os autores Pinheiro, Ceccim e Bur (2006) articular conceitos, percepções e sensações para produzir saberes sobre as práticas de ensino orientadas pela integralidade 
requer assumir a postura crítica e criativa de reconhecer possibilidades e colocar-se um desafio de "abertura de possíveis".

Na saúde isso significa interação, que se efetiva entre educação da saúde e trabalho em saúde, ousando uma contemporaneidade das práticas que somente existe em ato, não em reposição, antecipando a vivência da prática e contato com as pessoas que integram a sociedade, e que futuramente lhes será ofertado o serviço em saúde que se é aprendido enquanto acadêmico.

Dessa forma, para Watanabe (2003) a produção de conhecimento resultante dos saberes e das práticas do ensino e da saúde, para a integralidade, requer uma construção prática contextualizada em movimentos da vontade, capazes de alavancar uma teoria viva, que reflita, desde sua própria constituição, a experiência concreta da vida que lhe dá origem e da vida que vai originar, uma atividade prática, uma iniciativa da vontade, um movimento de transformação.

Durante a execução das atividades da operação, priorizou-se pela busca por articulações da participação na construção das redes de cuidado na integralidade da atenção e da inserção das linhas de cuidado como eixo estruturante do processo de formação; integralidade como organizadora do trabalho de equipe, dispositivos de formação na perspectiva de construção da rede de cuidado, previsão de atividades em vários níveis de complexidade, ancoradas na possibilidade de participação e vivência proporcionada pela estadia e pelo acolhimento fornecido pelo município.

\section{CONCLUSÕES}

A extensão é um dos pilares que constituem uma universidade. A importância de vincular projetos de extensão ao processo de ensino e aprendizado, é o que diferencia esse tipo de instituição das demais.

O Projeto Rondon Operação Porta do sol foi uma experiência singular, uma lição de vida e de cidadania. Segundo resultados do estudo, a área mais procurada pela comunidade foi a da saúde, o que reflete um dos pontos sensíveis da população brasileira em geral.

Cada um que fez parte da Operação Porta do Sol, tem suas impressões pessoais, suas lembranças e seu envolvimento junto a comunidade. Para os acadêmicos, é de extrema importância este contato, pois faz com que se ultrapasse os limites territoriais da instituição e se conheça um Brasil cheio de contrastes. 
A qualidade de vida dos indivíduos participantes, tanto a comunidade como os acadêmicos e professores envolvidos, certamente foi beneficiada. Porém, a contribuição principal foi o crescimento pessoal e a descoberta das potencialidades que o ser humano possui para lidar com as mais diversas situações.

\section{REFERÊNCIAS}

ALVES JUNIOR, E. D. (Org.). Envelhecimento e vida saudável 2. Rio de Janeiro: Apicuri, 2010.

MINISTÉRIO DA DEFESA. Programas e Projetos. Projeto Rondon - Lição de vida e de cidadania. Disponível em: <http://projetorondon.pagina-oficial.com/portal/>. Acesso em: 15 fev. 2016.

NEIRA, M. G.; NUNES, M. L. F. Pedagogia da cultura corporal: crítica e alternativas. São Paulo: Phorte, 2008.

PINHEIRO, R.; CECCIM, R. B.; MATTOS, R. A. Ensinar saúde: a integralidade e o SUS nos cursos de graduação na área da saúde. 2 ed. Rio de Janeiro: IMS/UERJ, 2006.

SHEPHARD, R. J. Envelhecimento, atividade física e saúde. São Paulo: Phorte, 2003.

SOUZA, O. S. S. A extensão universitária e as universidades populares. Revista da Faced, n. 9, p. 252-64, 2005. Disponível em: <www.portalseer.ufba.br/index.php/rfaced/article/view/2696/1906>. Acesso em: 14 mar. 2016.

TOMAS, R. N. A interação ensino, pesquisa e sociedade por meio da extensão universitária: uma experiência discente na partilha do conhecimento. Gestão e Conhecimento, v. 4, n. 1, art. 4, julho/novembro 2007. Disponível em: <www.pucpcaldas.br/graduacao/administracao/nupepu/online/inicial.htm>. Acesso em: 15 mar. 2016.

VIEIRA, R. S.; CERETTA, L. B. (Org.). Temas em direito sanitário \& saúde coletiva: SUS - uma política pública de estado. Criciúma, SC: Ed. UNESC, 2013.

WATANABE, T. Qualidade de vida e saúde. 4 ed. Criciúma, SC: Do autor, 2003. 